\title{
To Eat Or Not To Eat: Seafood Consumption Habit Formation
}

\author{
Maria Musarskaya ${ }^{1}$, Dawn Birch $^{2}$, and Juliet Memery ${ }^{1}$ \\ ${ }^{1}$ Department of Marketing, Faculty of Management, Bournemouth University, Poole, UK \\ ${ }^{2}$ School of Business, Faculty of Arts and Business, University of the Sunshine Coast, Sunshine \\ Coast, QLD, Australia
}

\begin{abstract}
Healthy development and nutritional sufficiency have long been linked to consumption of a wellbalanced diet, especially in primary school age children. Seafood products have been identified as a key component of a healthy diet. The consumption habits of a balanced and sustainable diet in children needs to be examined while taking into account family and environmental factors which influence eating habit formation in young children. The family setting is the first place where children acquire examples and principles of their own eating habits. Therefore, this study explores the effects of family eating habits on seafood consumption habit formation in children. Seafood intake diaries, pictures of consumed meals, as well as in-depth interviews formed a pilot study which included 4 families. The collected results were thematically analysed and underpinned by principles of the Theory of Planned Behaviour, Stages of Change Model, and Social Cognitive Theory. The pilot study results revealed an array of attitudes and preferences, norms (e.g. religion and parental duty), perceived drivers (e.g. health benefits) and perceived barriers (e.g. affordability and availability) which influence the formation of sustainable eating habits in children. A range of strategies (internal and external) for assisting appropriate eating habit formation including consumption of sustainable seafood by children are discussed.
\end{abstract}

Keywords: seafood consumption; ethical consumerism; sustainability; intervention strategies.

\section{Introduction}

A well-balanced diet is important for ensuring healthy nutrition, especially in young children, as eating habits established early in life tend to continue into adulthood (Janz, Burns, Levy, 2005; List \& Samek, 2015). In particular, seafood products have been proposed to be a key component of a healthy diet, as evidenced by UK government recommendations of two full servings of seafood per week (Wirfalt, 2013). In addition to government led initiatives for increased awareness of healthy eating habits, the seafood industry has recently witnessed increased attention given to sustainability issues including concerns about by-catch, overfishing, unclear labelling practices, and harmful fishing methods. As such, consumers are becoming more aware and concerned about ethical and sustainable seafood consumption (DEFRA, 2013; FishLove, 2016; RFBMR, 2012).

Given concerns about healthy diets for UK children (Affinita et al., 2013; Mikkilä, Räsänen, Raitakari, Pietinen, Viikari, 2005) and serious issues around declining fish stocks globally (Carrell, 2013; Harvey, 2013), it is paramount to increase UK families' awareness of the health benefits of including seafood in the diet. Furthermore, there is a need to select sustainable seafood to address both social and environmental consequences, and to positively influence healthy and ethical eating habit formation in young children. The family environment is the first and most crucial place where children are exposed to different food groups and eating patterns, and subsequently where enculturation of their own eating habits occurs. Indeed, there are strong links between family consumption habits and the eating habits developed in children.

As such, the purpose of this study is to explore sustainable seafood consumption habit formation in UK families and to identify intervention strategies which can assist the creation of such habits. 
Considering the nature of consumer behaviour (consumption habit formation of sustainable seafood), this study will implement an interpretive approach using qualitative methods. This research proposes a conceptual model based on aspects of social marketing theories which serves as the theoretical framework to review qualitative data collected from parents and children through interviews, food intake diaries and other projective research techniques.

\section{Conceptual Background}

While the majority of consumption interventions to improve nutrition have been geared toward adults, there is a growing need to consider nutritional decision-making among children (List \& Samek, 2015). Lack of proper nourishment, such as not meeting the recommended daily allowance requirements for fruits and vegetables, affects a child's health, hampers growth and contributes to a lack of concentration and energy, resulting in poor academic performance (Appleton et al., 2016; Jyoti, Frongillo, \& Jones, 2005; Weinreb et al., 2002; Whitaker, Phillips, \& Orzol, 2006). Consumption of a well-balanced diet, on the other hand, is important for ensuring healthy nutrition, especially in young children of primary school age, as it is early in life that people develop their eating habits (Janz et al., 2005; Mikkilä et al., 2005). Indeed, research suggests that healthy eating in childhood not only delivers nutrients sufficient for normal growth, psychophysical development and for the prevention of modern day diseases, but it also serves to foster healthy eating habits practiced in adulthood, such as consumption of sustainable seafood (Affinita et al., 2013; Birch \& Lawley, 2014; Mikkilä et al., 2005).

Fish and marine products are argued to be a key component of a healthy diet (Wirfalt, 2013). For example, a study conducted by Mozaffarian and Rimm (2006) revealed that people who regularly consume seafood reduce their risk of heart disease by $36 \%$. The UK government, through the NHS (2013), also proposed that fish and shellfish are an important part of a healthy diet. A well-balanced diet that includes a variety of fish and shellfish can contribute to heart health, children's growth and brain development, and hence, the NHS (2013) stated that a healthy diet should include at least two portions of fish a week including one oily fish, such as salmon or tuna.

The long-term health benefits for children of regular seafood consumption, as well as the necessity to implement sustainable and ethical seafood consumption habits, are evident. The primary method of instilling these practices and creating life-long habits, particularly in children, is through families. The family atmosphere is where young children are first exposed to different food groups and develop eating patterns through the process of enculturation (Grusec \& Hastings, 2007). Moreover, due to limited government budgets for school dinners, children typically eat fewer seafood meals at school (BBC, 2005; Prell, Berg, \& Jonsson, 2002), hence it is within the family environment where a child may often develop a sustainable and ethical seafood consumption habit. Many studies have emphasised the need to explore the effects of family eating habits on healthy consumption habit formation in children (Berge, Hoppmann, Hanson, \& Neumark-Sztainer, 2013; Conlon et al., 2015; Dunn, Jayaratne, Baughman, \& Levine, 2014; Van Grieken et al., 2013). Therefore, it is essential to determine the family circumstances which lead children to acquire healthy and sustainable eating habits associated with seafood (Dzielska, Kołoło, \& Mazur, 2008).

Given the decline of global fish stocks, seafood consumption should be from sustainable and ethical sources. This study aims to determine how family factors such as seafood meal frequency, attitudes toward sustainable seafood, enculturation, and ethical consumption affect consumption habit creation of sustainable seafood by primary school pupils aged 5-11 years, as it is at this age when children begin to form beliefs, attitudes, and consumption habits toward food (Intiful \& Lartey, 2014).

Although research has been conducted into individual's consumption of various food types, and in particular attitudes toward eating sustainable seafood (Hall \& Amberg, 2013; McManus, Merga, Newton, \& Trzesinski, 2010; McManus et al., 2012; Vázquez-Rowe, Villanueva-Rey, Moreira, \& Feijoo, 2013), there is a gap in knowledge when it comes to the role of the family in the formation of 
healthy eating habits associated with sustainable seafood consumption and the influence of family members on one another in relation to their overall sustainable seafood consumption. Exploring this gap will elicit knowledge in the context of families and sustainable seafood and more generally advance academic understanding of food habit formation and ethical consumption in terms of the importance of these two key aspects, healthy and sustainable eating patterns.

A review of the extant literature revealed a gap in terms of understanding sustainable seafood consumption habit formation in UK families, especially young children. Therefore, the following topics have been explored in the pilot study: overall current seafood consumption (including attitudes, preferences, involvement in purchase and preparation, etc.), understanding and applicability of the sustainable and ethical concept in terms of seafood consumption, influence of the family on seafood consumption, seafood purchase options, and potential past or future intervention strategies. Responses have provided initial understanding of what influences consumption habit formation and assisted in formulation of preliminary interventions which could lead to a positive change in consumers' behaviour in terms of increased levels of consumption of sustainable seafood. This research seeks to gather and assess further empirical evidence on behaviour change towards sustainable seafood consumption. Therefore, insights will be generated through gathering of information from best practices around the world as well as from suggestions provided by the participating families on which best practices might aid the consumer base in the UK to improve healthy habits of sustainable seafood consumption. Based on the preliminary results, it is evident that the proposed conceptual model and the chosen methodology will allow the researcher to collect rich data from both the parents and the children, and that the gathered data will answer research objectives.

\section{Methodology}

Based on the objectives of this research, the researcher has selected the interpretivist research philosophy to allow a rich analysis of eating habit formation and consumption of sustainable seafood by UK families, understand what causes or prevents such behaviour, and formulate insights for intervention strategies. Therefore, a qualitative study associated with an inductive approach was conducted to understand food habit formation of sustainable seafood in UK families.

A pilot study, which included 4 families (4 parents and 6 children), was conducted to ensure validity and clarity of the proposed methodology. In this pilot study, both primary and secondary data was collected to provide historical context about the topic and provide findings to add to the existing knowledge. A seafood intake dairy was kept by the participating families over a period of 1 month to record how often seafood was consumed, which species of seafood were consumed, whether or not the seafood packaging indicated if it was sustainable, the cooking style used, and the families' attitude toward the meal. Participating families also took pictures of the consumed seafood meals in order to help answer questions about specific meals during the in-depth interviews which were aimed to gather information about their consumption habits, consumption frequency, likes and dislikes of seafood meals, and family decision-making when it came to meal choice and preparation.

This pilot study involved face-to-face in-depth interviews as this method is deemed appropriate for gaining a more profound understanding of why people act in a certain way, and how they feel about it (Adams \& White, 2003). This method was chosen for its flexibility and the abundance of information about the causes of a particular behaviour, the consumption of sustainable seafood. Most of the questions in the interview were open-ended, enabling the participant to say as much or as little as they wished and all of the questions have been derived by identification of the knowledge gap in literature. In-depth interviews enabled the researcher to immediately ask follow-up questions if the information given by the interviewee seemed pertinent to the study. Data collected in the in-depth interviews was audio recorded and transcribed in NVIVO software, then thematically coded and analysed by the researcher. 
Due to the nature of this research, the target population were the parents of children aged 5-11 years and the children themselves. A non-probability sampling procedure was used, hence, individuals chosen for the study were selected randomly. Additionally, due to the fact that some populations of interest to this study were hard-to-reach and/or hidden, a snowball technique was used to generate the necessary number of participants.

\section{Findings of the Pilot Study}

Thematic analysis of the data from the pilot study was analysed within the theoretical framework of the Theory of Planned Behaviour commencing with a focus on attitudes, social norms and behavioural control with an impact on purchase intentions and consumption. In line with previous studies (Ajzen, 2011; Olsen, 2001), the data revealed a range of attitudes toward sustainable seafood consumption including: positive, negative, and misinformed. These findings arose from the conversations with parents as well as children, during which the participants expressed their positive attitudes by stating aspects of seafood they enjoyed, negative attitudes by stating specifics of seafood that was not as pleasant to them, and misinformed attitudes based on lack of knowledge about the benefits of seafood or the meaning of sustainable seafood.

The pilot study also revealed the influence of subjective norms such as religion and parental duty associated with eating seafood. These themes provide a deeper understanding of what drives parents to form the intention of consuming seafood. Equally, religious beliefs and parental sense of duty were seen as the cause for the parents to feel guilty about not feeding their families seafood.

Furthermore, the pilot study revealed three key areas of perceived behavioural control influencing sustainable seafood consumption; affordability and availability of sustainable seafood as well as general knowledge about cooking methods, health benefits, etc. As such, participants identified these themes to be key reasons for them not following through with their intention to prepare and consume sustainable seafood.

In addition, results from the pilot study revealed that enculturation, in terms of eating sustainable seafood, was influenced by environmental, personal, and behavioural factors, which has been echoed in previous studies (Cook 2009). Participants indicated that family atmosphere and older siblings impacted the consumption habit formation of the younger siblings. Furthermore, data gathered during the pilot study showed that a person's own understanding of their ability and knowledge of how to prepare and/or to consume seafood played an important role in the enculturation process during childhood.

Participants were aware of some strategies used by the industry to encourage seafood consumption, while some families have implemented specific 'reward' mechanisms to encourage their children to eat more healthily. As an example, one of the participating families awarded points to their children for good behaviour (such as finishing a seafood meal for dinner). Once a pre-agreed amount of points have been reached, the children would get a reward of their choice. This strategy has been proven to be successful in this particular case. The key emergent themes of intervention strategies were categorised as: known existing strategies, unknown existing strategies, and family strategies. By identifying and analysing intervention strategies, the researcher will be able to match specific strategies with various parts of the Stages of Change Model in further research, which in turn, will enable the researcher to identify which strategies might assist families in moving to a more favourable stage of the model, such as action or maintenance.

The pilot study revealed what UK consumers, in particular parents, think about the existing strategies, whether internal or external, in order to increase and encourage a greater consumption of sustainable seafood. Furthermore, the participants shared their opinion as to which intervention schemes and strategies are successful, who was responsible for these, and potential effectiveness of such strategies. 
From the pilot study, it is becoming evident as to what are the drivers and the barriers to sustainable seafood consumption by the parents and who or what influences habit trends in younger children (aged 5-11 years). For example, through the process of enculturation, it appears that factors such as family atmosphere, knowledge about the benefits of seafood, and the belief in one's ability to act in a specific manner provides children with the fundamental beliefs and attitudes which transform into habits which are then enculturated into child's long-term behaviour patterns. Furthermore, the findings provide explanations and examples to which intervention strategies (whether provided by the government, the industry, or the families) are known or not known, which strategies have the potential to improve and facilitate healthy consumption habits in UK families, and which strategies have been successful and to what extent.

\section{Conclusion and Implications}

Contribution to academic literature arising from this research will be greater understanding of sustainable seafood consumption habit formation in young children. Furthermore, this research will contribute to building knowledge and understanding of healthy and ethical consumption habits in families with young children more generally. The proposed conceptual model will be applicable to other contexts and could enhance further studies in the fields of consumption behaviour, habit formation, ethical consumerism, and healthy consumption habits.

In terms of the benefits for the industry, the results of this research will provide consumer critique of the current intervention strategies for encouraging sustainable seafood consumption and whether or not they are effective. Furthermore, recommendations will be made on what consumers are looking for from the industry and the government in order to assist them in making appropriate and ethical decisions in purchasing sustainable seafood. The newly gained knowledge may help guide policy makers and industry players alike. 


\section{Contributors}

Maria Musarskaya is a Lecturer in Marketing at Bournemouth University. Her research has focused on sustainable seafood consumption in the UK. Her PhD builds on this area of interest with a specific focus on the role of parents in creating healthy and ethical consumption behaviour among primary school children.

Dawn Birch is an Associate Professor in Postgraduate Business at the University of the Sunshine Coast, Queensland Australia who specialises in consumer behaviour. She researches and publishes in the areas of consumer behaviour related to food with a special interest in local and sustainable food and seafood. Dawn has undertaken research consultancies for CEFAS (UK) focusing on stakeholder perceptions of aquaculture, the Australian Queensland Government investigating consumer attitudes toward local food, and the Australian Seafood Cooperative Research Centre researching seafood consumption behaviour.

Juliet Memery is Professor in Marketing at Bournemouth University. Her early research examined the role of ethical and social responsibility issues in food and grocery shopping decisions in the UK. She continued this research, focusing in particular on food shopping behaviour with regard to ethical considerations, in both Europe and Australia. Themes emerging from this research resulted in further exploration of local and regional food, and seasonal food, with current work looking at food security, sustainable fish, food waste, and consumer decision-making models. 


\section{References}

Adams, J., \& White, M. (2003). Are activity promotion interventions based on the transtheoretical model effective? A critical review. British Journal of Sports Medicin, 37, 106-114.

Affinita A., Catalani L., Cecchetto G., De Lorenzo G., Dilillo D., Donegani G., Fransos L., Lucidi F., Mameli Ch., Manna E., Marconi E., Mele G., Minestroni L., Montanari M. Morcellini M., Rovera G., Rotilio G., Sachet M., \& Zuccotti G.V. (2013). Breakfast: a multidisciplinary approach. Italian Journal of Pediatrics, 39 (1), 44-53.

Ajzen, I. (2011), 'The theory of planned behaviour: Reactions and reflection', Psychology \& Health, 26(9), 1113-1127.

Appleton, K., Hemingway, A., Saulais, L., Dinnella, C., Monteleone, E., Depezay, L., Morizet, D., Armando Perez-Cueto, F., Bevan, A., \& Hartwell, H. (2016). Increasing vegetable intakes: rationale and systematic review of published interventions. European Journal Of Nutrition, 55 (3), 869-896.

BBC, (2005). BBC News Channel: School dinners around the world. Retrieved from: http://news.bbc.co.uk/1/hi/education/4298245.stm

Berge, J., Hoppmann, C., Hanson, C., \& Neumark-Sztainer, D. (2013). Research: Perspectives about Family Meals from Single-Headed and Dual-Headed Households: A Qualitative Analysis. Journal Of The Academy Of Nutrition And Dietetics, 113, 1632-1639.

Birch, D., \& Lawley, M. (2014). The role of habit, childhood consumption, familiarity, and attitudes across seafood consumption segments in Australia. Journal Of Food Products Marketing, 20 (1), 98113.

Carrell, S. (2013). Fears for Scottish salmon farming after China production targets missed. Retrieved from: http://www.theguardian.com

Conlon, B., McGinn, A., Lounsbury, D., Diamantis, P., Groisman-Perelstein, A., Wylie-Rosett, J., \& Isasi, C. (2015), 'The role of parenting practices in the home environment among underserved youth', Childhood Obesity, 11, 4, pp. 394-405.

Cook, D. (2009), 'Children's Subjectivities and Commercial Meaning: The Delicate Battle Mothers Wage When Feeding Their Children', in A. James, A Trine Kjørholt, and V. Tinstad (eds.), Children, Food and identity in Everyday Life. London: Palgrave Macmillan.

DEFRA, (2013). Policy. Retrieved from: https://www.gov.uk/government/news/sustainable-fishing-uksecures-deal-at-eu-negotiations

Dunn, C., Jayaratne, K., Baughman, K., \& Levine, K. (2014). 'Teaching Basic Cooking Skills: Evaluation of the North Carolina Extension Cook Smart, Eat Smart Program'. Journal Of Family \& Consumer Sciences, 106, 1, pp. 39-46.

Dzielska A., Kołoło H., \& Mazur J. (2008). Health behaviours of adolescents associated with nutrition in the context of socioeconomic factors - trends between 2002 and 2006. Problemy Higieny $i$ Epidemiologii, 89 (2), 222-229.

FishLove, (2016). Love Fish? Campaign. Retrieved from: https://fishlove.co.uk/

Grusec, J.E., \&Hastings, P.D. (2007). Handbook of Socialization: Theory and Research. Guilford Press. 
Hall, T., \& Amberg, S. (2013). Research report: Factors influencing consumption of farmed seafood products in the Pacific northwest. Appetite, 66, 1-9.

Harvey, F. (2013). Discards ban 'no great victory' for fish stocks, says expert. Retrieved from: http://www.theguardian.com

Intiful, F., \& Lartey, A. (2014). 'Breakfast habits among school children in selected communities in the eastern Region of Ghana', Ghana Medical Journal, 48, 2, pp. 71-77.

Janz, K. F., Burns, T. L., \& Levy, S. M. (2005). Tracking of activity and sedentary behaviors in childhood: The lowa bone development study. American Journal of Preventive Medicine, 29, 171178.

Jyoti, D., Frongillo, F., \& Jones, S. (2005). Food insecurity affects school children's academic performance, weight gain, and social skills. Journal of Nutrition, 135, 2831-2839.

List, J, \& Samek, A. (2015). The behavioralist as nutritionist: Leveraging behavioral economics to improve child food choice and consumption. Journal Of Health Economics, 39, 135-146.

McManus, A., Merga, M., Newton, W., \& Trzesinski, A. (2010). Seafood: nutritional gold for seniors. Australasian Medical Journal, 3 (13), 855-859.

McManus, A., Hunt, W., Howieson, J., Cuesta-Briand, B., McManus, J., \& Storey, J. (2012). 'Attitudes towards seafood and patterns of consumption in an Australian coastal town. Nutrition Bulletin, 37 (3), 224-231.

Mikkilä, V., Räsänen, L., Raitakari, O.T., Pietinen, P., \& Viikari, J. (2005). Consistent dietary patterns identified from childhood to adulthood: The Cardiovascular Risk in Finns Study. British Journal of Nutrition 93, 923-931.

Mozaffarian, D. \& Rimm, E. (2006). Fish intake, contaminants, and human health: evaluating the risks and the benefits. Jama, 296 (15), 1885-1899.

NHS (2013). Fish and shellfish. Retrieved from: http://www.nhs.uk/livewell/goodfood/pages/fishshellfish.aspx

Olsen, S. O. (2001), 'Consumer involvement in seafood as family meals in Norway: An application of the expectancy-value approach', Appetite, 36, 173-186.

Prell, H., Berg, C., \& Jonsson, L. (2002). Why don't adolescents eat fish? Factors influencing fish consumption in school. Scandinavian Journal Of Nutrition, 46 (4), 184-191.

RFBMR (2012). Seafood. Restaurant, Food \& Beverage Market Research Handbook, 284-286.

Van Grieken A., Veldhuis L., Renders C.M., Borsboom G.J., van der Wouden J.C., Hirasing RA, et al. (2013). Population-Based Childhood Overweight Prevention: Outcomes of the 'Be Active, Eat Right' Study. PLoS ONE 8(5): e65376. doi:10.1371/journal.pone.0065376

Vázquez-Rowe, I., Villanueva-Rey, P., Moreira, M., \& Feijoo, G. (2013).'The role of consumer purchase and post-purchase decision-making in sustainable seafood consumption. A Spanish case study using carbon footprinting', Food Policy, 41, 94-102.

Weinreb.L., Wehler.C., Perloff. J., Scott, R., Hosmer, D., Sagor, L., \& Gundersen, C. (2002). Hunger: its impact on children's health and mental health. Pediatrics, 110, 41. 
Whitaker, R., Phillips, S., \&Orzol, S. (2006). Food insecurity and the risks of depression and anxiety in mothers and behavior problems in their preschool-aged children. Pediatrics, 118 (3), 859-868.

Wirfalt, E., Drake, I., \& Wallstrom, P. (2013). What do review papers conclude about food and dietary patterns? Food \& Nutrition Research, 57. 